\title{
Produção e tolerância ao pendoamento de alface-romana em diferentes ambientes ${ }^{1}$
}

\author{
Cárita Rodrigues de Aquino², Santino Seabra Junior ${ }^{3}$, Elisangela Clarete Camilit, \\ Marla Silvia Diamante ${ }^{5}$, Ediberto Sena Costa Pinto ${ }^{6}$ \\ http://dx.doi.org/10.1590/0034-737X201461040016
}

\begin{abstract}
RESUMO
O experimento foi conduzido na área experimental da Universidade do Estado de Mato Grosso, localizada no município de Cáceres-MT, no período de maio a agosto de 2011, com o objetivo de avaliar a influência de diferentes ambientes e espaçamentos na produção e tolerância ao pendoamento de alface-romana cultivar Sophia. O delineamento experimental foi em blocos casualizados, arranjados em esquema fatorial $2 \times 5$, composto por dois espaçamentos ( 30 x $30 \mathrm{~cm}$ e $25 \times 25 \mathrm{~cm}$ ) e cinco ambientes de cultivo (tela de sombreamento 30 e $50 \%$, tela termorrefletora de 30 e $50 \%$ e ambiente aberto), perfazendo 10 tratamentos com quatro repetições cada. As parcelas experimentais foram constituídas por quatro linhas, com cinco plantas cada, totalizando 20 plantas por parcela. Consideraram-se como área útil para avaliação da produção as seis plantas centrais. As parcelas em que foi utilizado o espaçamento $30 \times 30 \mathrm{~cm}$ apresentavam $1,8 \mathrm{~m}^{2}$ cada, e as com o espaçamento $25 \times 25 \mathrm{~cm}, 1,5 \mathrm{~m}^{2}$ cada. As mudas foram transplantadas com 26 dias e a colheita realizada aos 46 dias após o transplantio. Observou-se que o espaçamento de $25 \times 25 \mathrm{~cm}$ entre plantas e o ambiente aberto proporcionaram maior produtividade da alface-romana. Porém, o tempo para pendoamento das plantas no ambiente aberto foi menor que nos ambientes com as telas de sombreamento ou termorrefletora.
\end{abstract}

Palavras-chave: Lactuca sativa, incidência de luz, cultivo protegido, florescimento, espaçamento.

\section{ABSTRACT}

\section{Production and early bolting tolerance of romaine lettuce in different environments}

The experiment was conducted at the Universidade Federal de Mato Grosso experimental area, in Cáceres, Mato Grosso State, from May to August 2011, with the objective of evaluating the influence of different environments and spacings in the production and tolerance to early bolting of romaine lettuce cultivar Sophia. The experimental design used was a randomized block design in a $2 \times 5$ factorial design, with two spacings $(30 \times 30 \mathrm{~cm}$ and $25 \times 25 \mathrm{~cm})$ and five protected environments (with 30 and 50\% shade screens, 30 and 50\% thermo-reflective screens and an open field), totaling ten treatments with four replicates each. The plots consisted of four rows with five plants each, totaling twenty plants per plot. The six central plants were considered as useful area for yield evaluation. The plots that used the spacing $30 \times 30 \mathrm{~cm}$ had $1.8 \mathrm{~m}^{2}$ each, and the $25 \times 25 \mathrm{~cm}$ plots had $1.5 \mathrm{~m}^{2}$ each. Seedlings were transplanted at 26 days and the crop was harvested 46 days after transplanting. The $25 \times 25 \mathrm{~cm}$ spacing between plants and the open field provided the highest yield of romaine lettuce. However, the time for early bolting of plants in open field was shorter than in environments with shading screens or thermo-reflective screens.

Key words: flowering, greenhouse crops, Lactuca sativa spacing, light incidence.

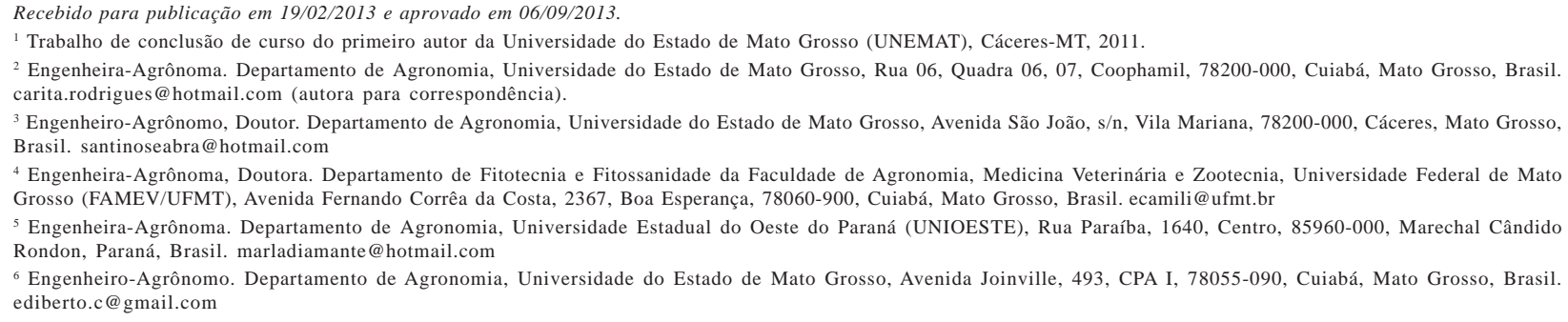




\section{INTRODUÇÃO}

Por ser uma espécie originária de clima temperado, a alface enfrenta dificuldades de adaptação em locais de temperatura e luminosidade elevadas, o que dificulta seu crescimento, e impede a expressão do potencial genético da espécie (Bezerra Neto et al., 2005).

No município de Cáceres, Estado de Mato Grosso, as médias anuais de temperatura atingem $31,5^{\circ} \mathrm{C}$ (Neves et $a l ., 2011)$, o que dificulta a adaptação de cultivares de alface, pois, segundo Puiatti \& Finger (2005), a faixa de temperatura adequada para a cultura é de 4 a $27{ }^{\circ} \mathrm{C}$.

Temperaturas elevadas estimulam o pendoamento precoce da alface, o que acarreta o alongamento do caule, reduz o número de folhas, afeta a formação da cabeça comercial e estimula a produção de látex (Cock et al., 2002), deixando as folhas amargas, mais rígidas e antecipa seu ciclo reprodutivo (Luz et al., 2009), resultando na depreciação do produto e prejuízos financeiros.

Diante dos fatos apresentados, uma alternativa para o cultivo dessa hortaliça é a utilização do ambiente protegido, onde se tem a diminuição na sazonalidade da oferta, podendo oferecer produtos de qualidade o ano todo (Martins, 2007). As telas de sombreamento têm sido cada vez mais utilizadas com o objetivo de reduzir a incidência direta dos raios solares, proporcionar temperaturas mais amenas e minimizar o efeito de chuvas e ventos fortes (Bezerra, 2003), favorecendo o cultivo em condições tropicais.

As telas termorrefletoras, além de promoverem sombreamento, são metalizadas com alumínio em ambas as faces, o que permite reflexão de parte da energia solar, tornando possível obter menores temperaturas no verão e maiores no inverno, além de promover a difusão de luz e aumentar a eficiência da fotossíntese (Costa, 2004). Segundo Rodrigues et al. (2009), a utilização de técnicas de cultivo é importante para os produtores que buscam alternativas para aumentar a produtividade.

Santos et al. (2010), ao avaliarem as variações de luminosidade e temperaturas do ar e do solo em diferentes ambientes de cultivo tipo telado, em Cáceres-MT, observaram que o uso das telas de sombreamento e termorrefletoras foi eficiente na redução da luminosidade e temperatura do ar e do solo, demonstrando ser viável o uso dessas telas em condições tropicais. Seabra Junior et al. (2009), avaliando a produção de cultivares de alface crespa sob diferentes telas de sombreamento, verificaram tendência de maior produtividade nos ambientes com maior porcentagem de sombreamento, principalmente com tela termorrefletora $50 \%$, já que nesses ambientes houve diminuição da temperatura ambiental.

Além das condições climáticas, o fator espaçamento também influencia significativamente a produção da alfa- ce; espaçamentos mais adensados acarretam maior competição por luminosidade, devido ao sombreamento que as plantas causam umas sobre as outras, diminuindo a taxa fotossintética e ocasionando redução da produção por planta (Lima et al. 2004). No entanto, a redução do espaçamento entre plantas possibilita o cultivo de maior número de plantas por área, proporcionando aumento da produtividade (Silva et al. 2000). Segundo Filgueira (2007), o espaçamento ideal para a alface, o qual deve ser utilizado nos canteiros definitivos, é de 25 a 30 x 25 a $30 \mathrm{~cm}$.

Com este trabalho objetivou-se avaliar a influência de diferentes ambientes e espaçamentos na produção e tolerância ao pendoamento da alface-romana.

\section{MATERIAL E MÉTODOS}

O experimento foi conduzido na área experimental de horticultura da Universidade do Estado de Mato Grosso (UNEMAT), campus de Cáceres-MT, situada a uma altitude média de 118 metros, latitude $16^{\circ} 04^{\prime} 43^{\prime \prime}$ S e longitude $57^{\circ} 40^{\prime} 51^{\prime \prime} \mathrm{W}$.

O clima da região é classificado como Tropical, com temperatura máxima anual de $31,5^{\circ} \mathrm{C}$ e mínima média de $20,1^{\circ} \mathrm{C}$, podendo ocorrer temperaturas de até $41^{\circ} \mathrm{C}$. A pluviosidade anual é de aproximadamente $1.300 \mathrm{~mm}$, concentrando $76 \%$ nos meses de novembro a abril (Neves et al., 2011). Na Figura 1 são apresentados os dados de temperaturas máxima, mínima e média do ar durante o período de cultivo, registradas pelo Instituto Nacional de Meteorologia em Cáceres/MT.

O solo da área experimental é do tipo Plintossolo Pétrico Concrecionário distrófico. Este solo, na camada de 0 a $0,2 \mathrm{~m}$, é composto por areia $\left(617 \mathrm{~g} \mathrm{~kg}^{-1}\right)$, silte (145 g $\mathrm{kg}^{-1}$ ) e argila (337 $\left.\mathrm{g} \mathrm{kg}^{-1}\right)$, apresentando as seguintes características químicas: M.O. $=28,0 \mathrm{~g} \mathrm{dm}^{-3} ; \mathrm{pH}=6,1 ; \mathrm{P}(\mathrm{mg}$ $\left.\mathrm{dm}^{-3}\right)=90,5 ; \mathrm{K}\left(\mathrm{cmolc} \mathrm{dm}^{-3}\right)=0,33 ; \mathrm{Ca}\left(\mathrm{cmolc} \mathrm{dm}^{-3}\right)=5,19$; $\mathrm{Mg}\left(\mathrm{cmolc} \mathrm{dm}^{-3}\right)=1,94 ; \mathrm{Al}=0,0\left(\mathrm{cmolc} \mathrm{dm}^{-3}\right) ; \mathrm{CTC}=8,3$ $\left(\mathrm{cmolc} \mathrm{dm}^{-3}\right.$ ) e V $=89,40 \%$.

O delineamento experimental foi em blocos casualizados, em esquema fatorial $2 \times 5$, sendo dois espaçamentos ( $30 \times 30$ e $25 \times 25 \mathrm{~cm}$ ) e cinco ambientes de cultivo (tela de sombreamento de 30 e $50 \%$, tela termorrefletora de 30 e $50 \%$ e ambiente aberto), perfazendo um total de 10 tratamentos, com quatro repetições.

As parcelas experimentais foram constituídas por quatro linhas, com cinco plantas cada, totalizando 20 plantas por parcela. Consideraram-se como área útil para avaliação da produção as seis plantas centrais, e as demais plantas para avaliação de tolerância ao pendoamento. As parcelas em que foi utilizado o espaçamento $30 \times 30 \mathrm{~cm}$ apresentavam $1,8 \mathrm{~m}^{2}$ cada, e aquelas com o espaçamento $25 \times 25 \mathrm{~cm}, 1,5 \mathrm{~m}^{2}$ cada. Os canteiros com $0,2 \mathrm{~m}$ de altura, 9,0 m de comprimento e 1,5 $\mathrm{m}$ de largura foram levantados 
nos ambientes de cultivo com dimensão de $100 \mathrm{~m}^{2}(10$ x 10 $\mathrm{m})$, com pé direito de 2,4 $\mathrm{m}$ de altura.

A semeadura em bandejas de poliestireno expandido com capacidade para 128 células, preenchidas com substrato comercial Basaplant ${ }^{\circledR}$, foi efetuada no dia 02/ 05/2011, utilizando-se o cultivar Sophia (SAKATA), que é do grupo Romana. Após a semeadura, as bandejas permaneceram em ambiente protegido, cobertas com filme plástico agrícola (polietileno) até o transplante.

O transplante foi realizado aos 26 dias após a semeadura (DAS), com quatro linhas de cultivo por canteiro nos espaçamentos de $25 \times 25$ e $30 \times 30 \mathrm{~cm}$, totalizando 133.333 e 84.844 plantas ha $^{-1}$, respectivamente.

A adubação foi realizada de acordo com a análise do solo e nas recomendações para alface (Trani et al.,1996), utilizando-se $40 \mathrm{~kg} \mathrm{ha}^{-1}$ de N, $200 \mathrm{~kg} \mathrm{ha}^{-1}$ de $\mathrm{P}_{2} \mathrm{O}_{5}$ e $50 \mathrm{~kg}$ $\mathrm{ha}^{-1}$ de $\mathrm{K}_{2} \mathrm{O}$, fornecidos pelo formulado 04-14-08 e Superfosfato Simples $\left(18 \% \mathrm{P}_{2} \mathrm{O}_{5}\right)$. Para adubação de cobertura utilizou-se ureia $(44 \% \mathrm{~N})$ como fonte de nitrogênio na dose de $90 \mathrm{~kg} \mathrm{ha}^{-1}$ de $\mathrm{N}$, parcelado em quatro aplicações, aos 7, 14, 21 e 28 dias após o transplante (DAT).

A irrigação utilizada foi por aspersão, com mangueira Tipo Santeno, duas vezes ao dia, e o controle de plantas daninhas foi realizado por meio de capina manual, sempre que necessário.

As temperaturas máximas do ar (T. Máx. Ar) e do solo (T. Máx. Solo) foram coletadas diariamente, entre 12 e 13 $\mathrm{h}$, durante o período de cultivo. Essas foram registradas com termo-higrômetro modelo HT-208, instalado a 1,0 m do solo no centro do ambiente, para temperatura do ar, e termômetro tipo espeto, portátil modelo TEC-1311, na profundidade de $15 \mathrm{~cm}$, para temperatura do solo.

A colheita da alface foi realizada no dia 13/07/2011 (46 DAT). As plantas foram levadas ao laboratório, onde foram avaliados a massa fresca total, obtida pela pesagem das plantas, e o número de folhas externas (folhas da saia). Posteriormente, foram retiradas as folhas externas (ve- lhas e danificadas), avaliando-se a massa fresca comercial (g planta ${ }^{1}$ ), o diâmetro da planta $(\mathrm{cm})$, comprimento do caule $(\mathrm{cm})$, número de folhas comerciais e a massa seca, e estimou-se a produtividade.

Devido à ocorrência da doença mancha-de-cercóspora, ocasionada pelo fungo Cercospora longissima, identificada por meio da leitura da incubação das folhas com o sintoma, realizou-se a avaliação no dia da colheita do número de folhas com sintoma e a severidade da doença utilizando-se a escala diagramática elaborada por Gomes et al. (2004) para cercosporiose de alface, representada pelos valores de 1, 3, 6, 11, 20, 34, 51, e 68\% de área foliar lesionada.

Para avaliar a tolerância ao pendoamento, foi considerado o número de dias da semeadura até o ponto de “espigamento", que consiste no alongamento do caule e início da formação das estruturas florais (Luz et al., 2009).

A compacidade da cabeça foi avaliada por um sistema de notas de 0 a 5 definidas para alface-americana. Nota 0 : ausência total de cabeça formada; nota 1: cabeça sem miolo definido; nota 2: cabeça com miolo aparente e folhas periféricas soltas; nota 3: miolo definido e folhas iniciando a compactação na periferia; nota 4: miolo definido e folhas da periferia compactas, mas permitindo individualização visual; e nota 5: miolo compacto e sem individualização visual das folhas periféricas (adaptado de Hotta, 2008).

Os dados foram submetidos à análise de variância pelo teste F, e as médias foram comparadas pelo teste de Tukey a 5\% de probabilidade, utilizando-se o sistema Assisat (Silva \& Azevedo, 2002).

\section{RESULTADOS E DISCUSSÃO}

Houve interação significativa para os fatores ambientes e espaçamentos somente para a característica produtividade (Tabela 1).

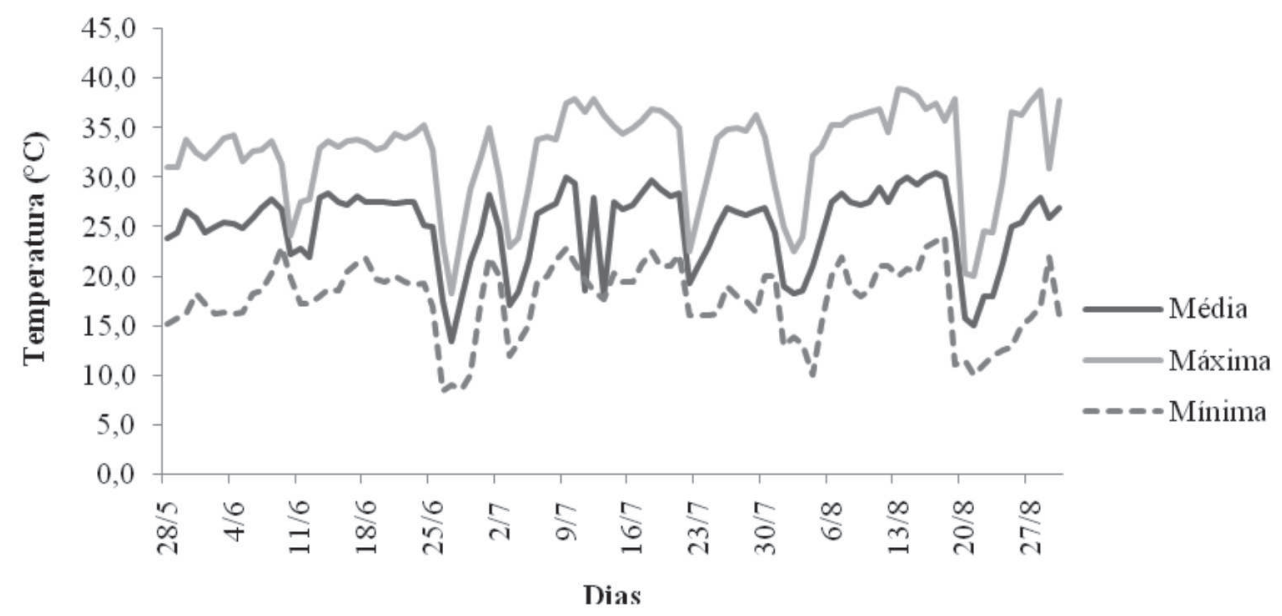

Figura 1. Temperaturas máxima, média e mínima do ar no período de 28/05/2011 a 27/08/2011, dados adaptados do INMET (2011) para Cáceres/MT, 2011. 


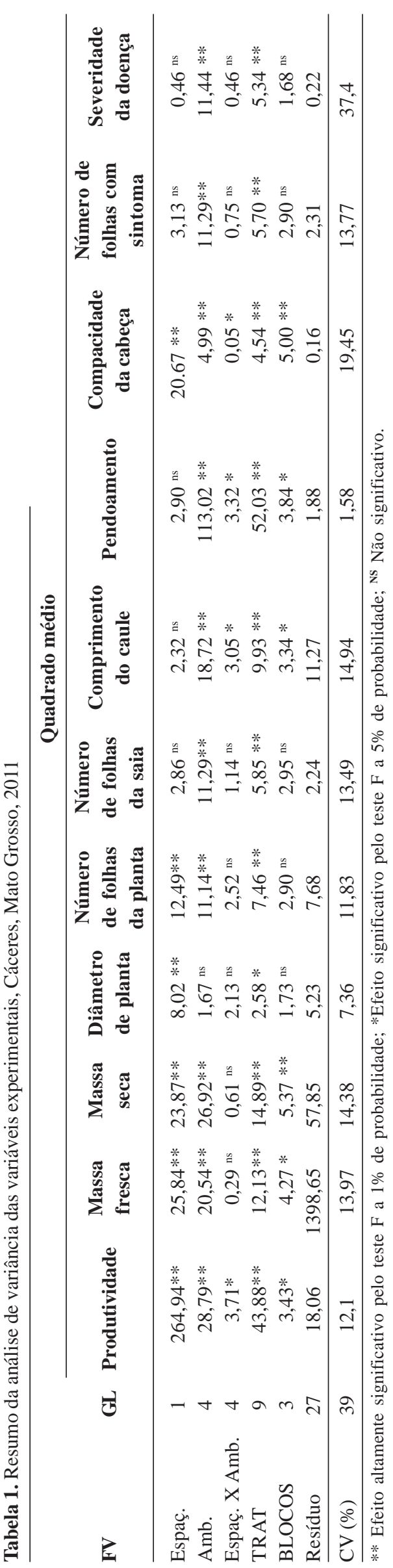

Verifica-se que no menor espaçamento, ou seja, a maior densidade de plantio ( $25 \times 25 \mathrm{~cm})$, houve maior produtividade de alface em todos os ambientes. Porém, quando se comparam os ambientes na maior densidade de plantio verifica-se que as plantas cultivadas no campo aberto e em tela termorrefletora de $30 \%$ foram as mais produtivas, sem diferir do tratamento com tela de sombreamento $30 \%$ (Tabela 2). Isso pode ter ocorrido devido à maior intensidade luminosa nesses ambientes e maior difusão de luz nas telas com $30 \%$ de sombreamento em relação à de $50 \%$ (Santos et al. 2010).

A tendência de maior produtividade em espaçamentos mais adensados também foi observada por Silva et al. (2000) avaliando o comportamento de cultivares de alface em diferentes espaçamentos. De acordo com Echer et al. (2001), à medida que o espaçamento diminui a densidade populacional aumenta e há tendência de elevar a produtividade.

As médias de produtividade variaram entre $24,20 \mathrm{e}$ $46,11 \mathrm{tha}^{-1}$ para os espaçamentos de $30 \times 30 \mathrm{~cm}$ e $25 \times 25$ $\mathrm{cm}$, respectivamente (Tabela 2). Tosta et al. (2009), ao avaliarem quatro cultivares de alface (Great Lakes, Hortência, Regina e Quatro Estações) em ambiente aberto no período de abril a junho, em Cassilândia-MS, obtiveram médias de 20,47 a 42,96 tha ${ }^{-1}$ utilizando o espaçamento $35 \times 35 \mathrm{~cm}$. Jasse et al. (2006), ao estudarem diferentes tipos de alface em sistemas agroecológicos no período de agosto a novembro, em Brasília-DF, obtiveram média inferior comparando à deste trabalho, sendo de $22,43 \mathrm{t} \mathrm{ha}^{-1}$ para alfaceromana, utilizando espaçamento $30 \times 35 \mathrm{~cm}$.

Quanto à produção de massa fresca, houve variação entre 206,04 e 335,21 $\mathrm{g}_{\text {planta }}{ }^{-1}$ entre os ambientes (Tabela 3), essa massa foi inferior à obtida por Tosta et al. (2009), que variaram de 263,23 a 552,37 g planta $^{-1}$ sem utilizar sombreamento. Entretanto, Schumacher et al. (2012), trabalhando com competição de cultivares de alface em JataíGO, no espaçamento $30 \times 30 \mathrm{~cm}$, em ambiente aberto, obteveram produção de massa fresca de alface romana Sophia igual a 256,08 g planta $^{-1}$, dentro do padrão de massa fresca apresentado neste trabalho.

Comparando a produção de massa fresca entre os ambientes, verifica-se que o ambiente aberto e a tela termorrefletora de $30 \%$ apresentaram as maiores massas frescas de plantas. Os demais ambientes (tela de sombreamento a 30 e $50 \%$ e termorrefletora a $50 \%$ ), com médias inferiores, não diferido estatisticamente entre si (Tabela 3). Seabra Junior et al. (2009), avaliando cinco cultivares de alface-crespa em diferentes ambientes, entre outubro e dezembro, em Cáceres-MT, observaram maior produção de massa fresca por planta quando cultivadas nos ambientes com maior porcentagem de sombreamento (tela de sombreamento e termorrefletora a 50\%). No entanto, em outro estudo realizado entre os meses de 
julho e setembro, com os mesmos cultivares e ambientes, não se observaram diferenças significativas na produção de massa fresca de alface cultivada nos diferentes ambientes, fato que se deve à diferença nas estações do ano em que foram realizados os trabalhos, uma vez que no inverno (julho a setembro) as temperaturas são amenas, propícias para o cultivo da alface (Seabra Junior et al., 2010). Isso explica o que ocorreu neste trabalho, que também foi realizado no período de inverno (maio a agosto), em que os ambientes menos sombreados proporcionaram maior produção de massa fresca (Tabela 3 ).

Apesar de o espaçamento mais adensado favorecer a produtividade por hectare, os maiores espaçamentos entre plantas corroboram para o aumento da massa fresca por planta de alface, como o que ocorreu neste trabalho (Tabela 3), por haver menor competição por água, luz e nutrientes, possibilita plantas maiores e mais pesadas, característica essa desejada, pois aumenta o valor de mercado.

A expressão do potencial genético de um cultivar depende das condições edafoclimáticas onde são produzidos os materiais, o que pode ter influenciado nos diferentes resultados para produção de massa fresca de plantas entre os trabalhos citados. A temperatura pode influenciar significativamente a cultura, alterando suas características (massa, qualidade) e, principalmente, sua produção (Silva et al., 2000). Porém, o melhoramento buscando resistência da cultura da alface a altas temperaturas tem evoluído no Brasil, e já são encontradas no mercado diversas opções de cultivares com essa característica (Santos, et al. 2009). Também tem sido observado que as empresas multinacionais têm dado preferência e prioridade em pesquisar e desenvolver o segmento de alface do grupo romana, assim como americana, mini e do tipo baby leaf (Costa \& Sala, 2012).

Durante o período de condução do experimento observaram-se temperaturas máximas do ar variando de 24,2 a $38,0^{\circ} \mathrm{C}$ e mínimas de 9,0 a $21,7^{\circ} \mathrm{C}$ (Figura 1) (INMET, 2009). As médias de temperatura verificadas nos diferentes ambientes às $13 \mathrm{~h}$ variaram de 29,8 a $35,6^{\circ} \mathrm{C}$ no ar e 23,1 a $25,4^{\circ} \mathrm{C}$ no solo (Figura 2). Seabra Junior et al. (2009), avaliando o cultivo de alface no verão em Cáceres-MT, sob temperaturas médias de 28,9 a $37,9^{\circ} \mathrm{C}$, obtiveram produção de massa fresca de alface-crespa de 76,2 a 177,5 g planta $^{-1}$. Santos et al. (2010), avaliando o desempenho de cultivares de alface tipo crespa sob altas temperaturas,

Tabela 2. Produtividade $\left(\mathrm{t} \mathrm{ha}^{-1}\right)$ de alface-romana Sophia, cultivada em cinco ambientes (campo aberto - CA, telas de sombreamento - TS 30\% e TS 50\% e telas termorrefletoras - TR 30\% e TR 50\%) e dois espaçamentos ( 30 x $30 \mathrm{~cm}$ e 25 x $25 \mathrm{~cm})$, em Cáceres, Mato Grosso, 2011

\begin{tabular}{lllll}
\hline & & \multicolumn{2}{c}{ Espaçamentos } & \multirow{2}{*}{ Médias } \\
\cline { 3 - 4 } & & $\mathbf{2 5} \mathbf{x} \mathbf{2 5}$ & $\mathbf{3 0} \mathbf{x} \mathbf{3 0}$ & 46,11 \\
\hline \multirow{3}{*}{ Ambientes } & CA & $60,45 \mathrm{aA}$ & $31,78 \mathrm{bA}$ & 32,47 \\
& TS 30\% & $41,52 \mathrm{aB}$ & $23,41 \mathrm{bAB}$ & 29,58 \\
& TS 50\% & $39,12 \mathrm{aB}$ & $20,05 \mathrm{bB}$ & 40,74 \\
& TR 30\% & $54,48 \mathrm{aA}$ & $27,00 \mathrm{bAB}$ & 26,76 \\
& TR 50\% & $34,77 \mathrm{aB}$ & $18,75 \mathrm{bB}$ & 24,20 \\
\hline
\end{tabular}

* Médias seguidas pelas mesmas letras maiúscula, na coluna, e minúscula, na linha, não diferem entre si pelo teste de Tukey (p < 0,05).

Tabela 3. Massa fresca e massa seca, diâmetro de planta (DP), número total de folhas da planta (NFP), número de folhas da saia (NFS) de alface-romana Sophia, cultivada em cinco ambientes (campo aberto - CA, telas de sombreamento - TS 30\% e TS 50\% e telas termorrefletoras - TR 30\% e TR 50\%) e dois espaçamentos (30 x $30 \mathrm{~cm}$ e 25 x $25 \mathrm{~cm}$ ), em Cáceres, Mato Grosso, 2011

\begin{tabular}{lcccccc}
\hline & & $\begin{array}{c}\text { Massa fresca } \\
\left(\mathbf{g ~ p l a n t a}^{-1}\right)\end{array}$ & $\begin{array}{c}\text { Massa seca } \\
(\mathbf{g})\end{array}$ & $\begin{array}{c}\text { DP } \\
(\mathbf{c m})\end{array}$ & NFP & NFS \\
\hline \multirow{4}{*}{ Ambientes } & CA & $335,21 \mathrm{a}$ & $71,25 \mathrm{a}$ & $32,56 \mathrm{a}$ & $27,15 \mathrm{a}$ & $14,06 \mathrm{a}$ \\
& TS 30\% & $243,85 \mathrm{~b}$ & $45,63 \mathrm{~b}$ & $31,00 \mathrm{a}$ & $23,40 \mathrm{ab}$ & $11,42 \mathrm{~b}$ \\
& TS 50\% & $225,19 \mathrm{~b}$ & $41,25 \mathrm{~b}$ & $30,11 \mathrm{a}$ & $20,90 \mathrm{~b}$ & $10,10 \mathrm{~b}$ \\
& TR 30\% & $327,92 \mathrm{a}$ & $64,38 \mathrm{a}$ & $31,60 \mathrm{a}$ & $26,13 \mathrm{a}$ & $9,75 \mathrm{~b}$ \\
& TR 50\% & $206,04 \mathrm{~b}$ & $41,88 \mathrm{~b}$ & $30,10 \mathrm{a}$ & $19,52 \mathrm{~b}$ & $10,13 \mathrm{~b}$ \\
\hline \multirow{2}{*}{ Espaçamento } & $30 \times 30$ & $297,70 \mathrm{~A}$ & $58,75 \mathrm{~A}$ & $32,10 \mathrm{~A}$ & $24,97 \mathrm{~A}$ & $11,49 \mathrm{~A}$ \\
& $25 \times 25$ & $237,58 \mathrm{~B}$ & $47,00 \mathrm{~B}$ & $30,05 \mathrm{~B}$ & $21,87 \mathrm{~B}$ & $10,69 \mathrm{~B}$ \\
\hline C.V.(\%) & & 16,09 & 17,24 & 17,62 & 12,91 & 14,74 \\
\hline
\end{tabular}

${ }^{*}$ Médias seguidas pela mesma letra não diferem entre si pelo teste Tukey $(\mathrm{p}<0,05)$.

Rev. Ceres, Viçosa, v. 61, n.4, p. 558-566, jul/ago, 2014 
também em Cáceres-MT, observaram produção de massa fresca média entre 52,5 e 111,5 $\mathrm{g} \mathrm{planta}^{-1}$ sob temperatura máxima de $35,3^{\circ} \mathrm{C}$.

Quanto à característica massa seca, observou-se a mesma tendência dos dados de produção de massa fresca onde o ambiente aberto e a tela termorrefletora $30 \%$ foram os que proporcionaram as maiores médias, 71,25 g e 64,38 $\mathrm{g}$, respectivamente (Tabela 3 ). Resultado que se assemelha aos obtidos por Santana et al. (2009), que observaram maiores médias de massa seca no cultivo a pleno sol em comparação com telas de sombreamento (30 e 50\%). Os autores relatam que a maior produção de massa seca das folhas pode ser atribuída à maior captação de luz.

Neste trabalho, o espaçamento menos adensado proporcionou maior produção de massa seca em relação ao espaçamento mais adensado (Tabela 3). Contrário a esses dados, Silva et al. (2000) observaram no espaçamento mais adensado $(20 \times 20 \mathrm{~cm})$ maior produção de massa seca, e à medida que se aumentou o espaçamento entre as plantas $(20 \times 25,20 \times 30,25 \times 25,25 \times 30,30 \times 30 \mathrm{~cm})$ houve decréscimo significativo na produção de massa seca da parte aérea.

O diâmetro médio das plantas não apresentou diferenças significativas nos diferentes ambientes, variando de 30,10 a 32,56 cm (Tabela 3). Porém, essas médias estão acima das obtidas por Santana et al. (2009) que, ao avaliarem a produção de alface-roxa em ambientes sombreados, observaram diâmetro da cabeça variando de 21,41 a $24,33 \mathrm{~cm}$, tendo as médias superiores sido as das plantas cultivadas a pleno sol e sob cobertura de tela de sombreamento $50 \%$. Por ser comercializada por unidade, atingir o máximo de área foliar em alface é uma característica decisiva durante a comercialização (Reghin et al., 2002).
Quanto ao espaçamento, o menos adensado proporcionou o maior diâmetro da planta (Tabela 3). Esse resultado está de acordo com o trabalho de Silva et al. (2000), que, avaliando o comportamento de cultivares de alface em diferentes espaçamentos, obtiveram maiores diâmetros de plantas quando cultivadas nos maiores espaçamentos $(20$ x 30, 25 x 30 e 30 x $30 \mathrm{~cm})$. Os autores relatam que maiores espaçamentos diminuem a competição entre plantas por água, luz e nutrientes, proporcionando plantas com maiores diâmetros.

O número de folhas é de grande importância tanto para o produtor, pois indica a adaptação do material genético ao ambiente, quanto para a comercialização (Diamante et al., 2013). Verificaram-se neste trabalho que no ambiente aberto e em aqueles com menor porcentagem de sombreamento (tela de sombreamento e termorrefletora a $30 \%$ ) foram encontradas as maiores médias (Tabela 3). Esses resultados que concordam com os de Bezerra Neto et al. (2005) ao estudarem a produtividade de alface em razão de sombreamento, temperatura e luminosidade elevadas, em Mossoró-RN. Esses autores observaram que sob tela de sombreamento as médias do número de folhas foram menores quando comparadas à do campo aberto.

O espaçamento menos adensado proporcionou maior média de número de folhas (24,97), em comparação com o espaçamento mais adensado (21,87 folhas por planta) (Tabela 3). Silva et al. (2000) não observaram diferenças significativas entre os diferentes espaçamentos quanto ao número de folhas por planta.

As folhas externas das plantas de alface que formam "cabeças" são denominadas folhas da "saia", e de acordo com Hotta (2008) elas protegem a cabeça da alface durante o transporte, sem depreciar o produto para

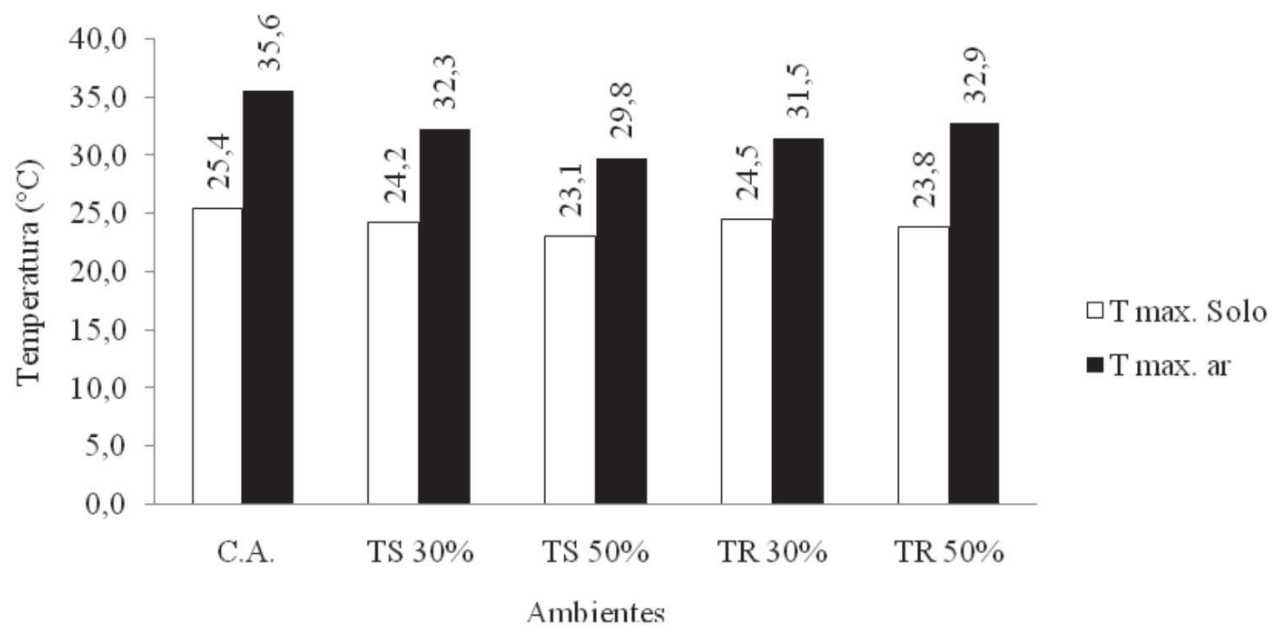

Figura 2. Temperaturas máximas médias do solo (T. máx. solo) e do ar (T. máx. ar) às 13 horas nos tratamentos: Campo Aberto (CA), Tela de Sombreamento 30\% (TS 30\%) e 50\% (TS 50\%), Tela Termorrefletora 30\% (TR 30\%) e 50\% (TR 50\%), aferidas entre 28 de maio e 7 de agosto de 2011, em Cáceres, Mato Grosso. 
comercialização no mercado. No presente trabalho, verificou-se que o campo aberto superou os ambientes sombreados para as médias de número de folhas da "saia" (Tabela 3) e, independentemente do espaçamento empregado, o número de folhas da "saia" não se alterou.

As médias de comprimento do caule das plantas no ambiente aberto e sob tela termorrefletora a $30 \%$ foram superiores às dos ambientes com tela de sombreamento $50 \%$ e tela termorrefletora 50\% (Tabela 4). Segundo Luz et al. (2009), o comprimento do caule das plantas pode ser considerado uma característica de verificação de tolerância ao pendoamento, o que pôde ser observado ao verificar que no campo aberto onde se encontrou maior média de comprimento de caule as plantas pendoaram antes, em comparação aos ambientes sombreados. No entanto, até o ponto de colheita, que nesse caso se deu aos 46 DAT e 72 DAS, não se observaram mudanças na aparência ou no formato comercial da planta que indicassem início de pendoamento. Entre os espaçamentos, as médias de comprimento do caule não diferiram estatisticamente.

O pendoamento precoce em alface relaciona-se à antecipação do ciclo reprodutivo e está associado a dias longos e altas temperaturas (Silva et al., 1999). Nesas condições ocorrem alterações nas características organolépticas da planta, como acentuado sabor amargo das folhas devido ao acúmulo rápido de látex, além de provocar redução da massa aérea (Souza et al., 2007). O município de Cáceres apresenta clima tropical com temperatura média máxima anual de $31,5^{\circ} \mathrm{C}$ (Neves et al., 2011), fator este que influencia negativamente o desempenho da planta de alface. A média máxima de temperatura observada a campo aberto foi de $35,6^{\circ} \mathrm{C}$ (Figura 2), o que acarretou a antecipação do ciclo reprodutivo nesse ambiente em comparação aos demais ambientes, apresentando a menor média de dias para o pendoamento das plantas (79,94 dias) (Tabela 4). Os ambientes com tela de sombreamento a $50 \%$ e tela termorrefletora a $50 \%$ proporcionaram às plantas mais dias de campo até o início do pendoamento, o que pode ser favorável caso ocorram atrasos na colheita.

Semelhante a este trabalho, Luz et al. (2009), avaliando genótipos de alface em ambientes de cultivo, observaram que o ambiente com tela termorrefletora $50 \%$, em comparação aos ambientes aberto, telas de sombreamento (30, 40 e $50 \%$ ) e telas termorrefletora (30 e 40\%), apresentou melhores condições para o cultivo da alface, visto que a maioria dos cultivares demorou mais para pendoar nesse ambiente. Os espaçamentos não influenciaram no número de dias para o pendoamento.

Para compacidade da cabeça, verificou-se maior média no ambiente com tela termorrefletora de $30 \%$ comparada ao mesmo material com $50 \%$ de sombreamento (Tabela 4). Essa característica de compacidade em alface do grupo americano está relacionada com o rendimento para o processamento, obtendo-se plantas com cabeças comerciais grandes e pesadas (Hotta, 2008). A alface-romana, assim como a americana, possui essa característica de formação de cabeça, no entanto forma cabeças mais fofas, que é característica desse grupo de alface, além de apresentar folhas mais crocantes, peculiaridade apreciada no mercado fresco.

Quando as plantas foram submetidas ao espaçamento menos adensado, elas apresentaram melhor desempenho na formação de cabeças (Tabela 4), isso pode ter ocorrido por haver menor competição entre plantas (Lima et al. 2004), o que garantiu maior número de folhas da "saia" e de folhas por planta (Tabela 2), proporcionando maior compacidade da cabeça (Tabela 4).

Verificou-se que os telados possibilitaram o controle da doença mancha-de- cercóspora, pois no ambiente aberto às plantas apresentaram maior suscetibilidade à doença, com maior número de folhas com sintoma e maior severidade ao ataque da doença (Tabela 4). Os espaçamentos não interferiram na doença.

Tabela 4. Comprimento do caule (CC), pendoamento, compacidade da cabeça, número de folhas com sintoma de mancha-decercóspora (NFCS) e severidade da doença (SD) em alface-romana Sophia, cultivada em diferentes ambientes (campo aberto - CA, telas de sombreamento - TS 30\% e TS 50\% e telas termorrefletoras - TR 30\% e TR 50\%), em dois espaçamentos (30 x $30 \mathrm{~cm}$ e 25 x $25 \mathrm{~cm}$ ), em Cáceres, Mato Grosso, 2011

\begin{tabular}{lcccccc}
\hline & & $\begin{array}{c}\text { CC } \\
(\mathbf{c m})\end{array}$ & $\begin{array}{c}\text { Pendoamento } \\
\text { (dias) }\end{array}$ & $\begin{array}{c}\text { Compacidade } \\
\text { da cabeça }\end{array}$ & NFCS & SD \\
\hline \multirow{4}{*}{ Ambientes } & CA & $29,97 \mathrm{a}$ & $79,94 \mathrm{~d}$ & $2,22 \mathrm{ab}$ & $14,06 \mathrm{a}$ & $1,20 \mathrm{a}$ \\
& TS 30\% & $21,71 \mathrm{bc}$ & $87,42 \mathrm{~b}$ & $2,00 \mathrm{ab}$ & $11,33 \mathrm{~b}$ & $1,00 \mathrm{~b}$ \\
& TS 50\% & $17,29 \mathrm{c}$ & $91,32 \mathrm{a}$ & $1,77 \mathrm{ab}$ & $9,90 \mathrm{~b}$ & $1,00 \mathrm{~b}$ \\
& TR 30\% & $24,92 \mathrm{ab}$ & $82,81 \mathrm{c}$ & $2,41 \mathrm{a}$ & $9,75 \mathrm{~b}$ & $1,00 \mathrm{~b}$ \\
& TR 50\% & $18,49 \mathrm{c}$ & $91,54 \mathrm{a}$ & $1,66 \mathrm{~b}$ & $10,13 \mathrm{~b}$ & $1,00 \mathrm{~b}$ \\
\hline Espaçamentos & $30 \times 30$ & $21,67 \mathrm{~A}$ & $86,24 \mathrm{~A}$ & $2,30 \mathrm{~A}$ & $11,46 \mathrm{~A}$ & $1,20 \mathrm{~A}$ \\
$(\mathrm{~cm})$ & $25 \times 25$ & $23,27 \mathrm{~A}$ & $86,98 \mathrm{~A}$ & $1,73 \mathrm{~B}$ & $10,61 \mathrm{~A}$ & $1,30 \mathrm{~A}$ \\
\hline & C.V.(\%) & 16,6 & 1,79 & 23,13 & 15,01 & 38,64 \\
\hline
\end{tabular}

* Médias seguidas pela mesma letra não diferem entre si pelo teste de Tukey $(\mathrm{p}<0,05)$.

Rev. Ceres, Viçosa, v. 61, n.4, p. 558-566, jul/ago, 2014 


\section{CONCLUSÕES}

1. O espaçamento $25 \times 25 \mathrm{~cm}$ proporcionou maior produtividade de alface-romana por hectare, no entanto o espaçamento $30 \times 30 \mathrm{~cm}$ possibilitou plantas maiores e com maior compacidade, o que poderá conferir ao olericultor melhores lucros.

2. Plantas de alface-romana cultivadas no ambiente aberto e sob tela termorrefletora a $30 \%$ apresentam maior massa fresca e maior produtividade, porém com maior comprimento de caule; ou seja, menor tolerância ao pendoamento.

3. As telas de sombreamento e termorrefletora a $50 \%$ aumentaram a tolerância das plantas ao pendoamento.

4. O ambiente com telas de sombreamento e termorrefletora reduziu o ataque da mancha-de-cercóspora nas plantas de alface.

\section{REFERÊNCIAS}

Bezerra Neto F, Rocha RCC, Negreiros MZ de, Rocha RHC \& Queiroga RCF de (2005) Produtividade de alface em função de condições de sombreamento e temperatura e luminosidade elevadas. Horticultura Brasileira, 23:189-192.

Bezerra FC (2003) Produção de mudas de hortaliças em ambiente protegido. Fortaleza, Embrapa Agroindústria Tropical. 22p. (Documentos, 72).

Cock WRS, Amaral Junior AT, Smith REB \& Monnerat PH (2002) Biometrical analysis of phosphorus use efûciency in lettuce cultivars adapted to high temperatures. Euphytica, 126: 299308

Costa CP \& Sala FC (2012) Retrospectiva e tendência da alfacicultura brasileira. Horticultura Brasileira, 30:187-194.

Costa VM (2004) Desenvolvimento de mudas de cafeeiro produzidas em tubetes, sob malhas termo-refletoras e malha negra. Dissertação de Mestrado. Escola Superior de Agricultura "Luiz de Queiroz", Piracicaba. 79p.

Diamante MS, Seabra Junior S, Inagaki AM, Silva MB \& Dallacort R (2013) Produção e resistência ao pendoamento de alfaces tipo lisacultivadas sob diferentes ambientes. Revista Ciência Agronômica, 44:133-140.

Echer MM, Guimarães VF, Goto R \& Purquerio LFV (2001) Comportamento de cultivares de alface em função do espaçamento. Revista de Agricultura, 76:267-275.

Filgueira FAR (2007) Novo manual de olericultura: agrotecnologia moderna na produção e comercialização de hortaliças. $3^{a}$ ed. Viçosa, Universidade federal de Viçosa. 421p.

Gomes AMA, Michereff SJ \& Mariano RLR (2004) Elaboração e validação de escala diagramática para cercosporiose da alface, Summa Phytopathologica, 30:1

Hotta LFK (2008) Interação de progenies de alface do grupo americano por época de cultivo. Dissertação de Mestrado. Universidade Estadual Paulista, Botucatu. 98p.

Instituto Nacional de Meteorologia (2009) Dados de temperatura máximas, médias e mínimas/estação meteorológica de CáceresMT. Disponível em: <http:// www.inmet.gov.br/temperatura/ caceres.html>. Acessado em: 07 de setembro de 2011.
Jasse MEC, Oliveira SF de, Resende FV \& Vidal MC (2006) Produção de cultivares de alface dos tipos lisa, crespa e americana em sistema agroecológico. Horticultura Brasileira, 24:2.

Lima AA, Miranda EG, Campos LZO, Cuznato Júnior WH, Melo SC \& Camargo MS (2004) Competição das cultivares de alface Vera e Verônica em dois espaçamentos. Horticultura Brasileira, 22:314-316

Luz AO, Seabra Júnior S, Souza SBS de \& Nascimento AS (2009) Resistência ao pendoamento de genótipos de alface em ambientes de cultivo. Agrarian, 2:71-82.

Martins G (2007) Cultivo em ambiente protegido - o desafio da plasticultura. In: Filgueira FAR (Ed.) Novo manual de olericultura: agrotecnologia moderna na produção e comercialização de hortaliças. $3^{a}$ ed. Viçosa, Universidade Federal de Viçosa. 421p.

Neves SMAS, Neves RJ \& Mercante MA (2011) Dinâmica da paisagem na região nordeste de Cáceres-MT, com suporte nas geotecnologias. In: Rodrigues SC (Ed.) Paisagens do pantanal e do cerrado: fragilidades e potencialidades. Uberlandia, EDUFU. p.153-177.

Puiatti M \& Finger FL (2005) Fatores climáticos. In: Paulo CRF (Ed.) Olericultura-teoria e prática. Rio Branco, Suprema Gráfica e Editora. p.17-38.

Reghin MY, Dalla Pria M, Otto RF, Feltrim AL \& Vinne J (2002) Sistemas de cultivo com diferentes espaçamentos entre plantas em alface mini. Horticultura Brasileira, 20:2.

Rodrigues DS, Nomura ES \& Garcia VA (2009) Coberturas de solo afetando a produção de alface em sistema orgânico. Revista Ceres, 53:332-335.

Santana CVS, Almeida AC \& Turco SHN (2009) Produção de alface roxa em ambientes sombreados na região do submédio São Francisco - BA. Revista Verde, 4:01-06.

Santos CL, Seabra Júnior S, Lalla JG de, Theodoro VC de A \& Nespoli A (2009) Desempenho de cultivares de alface tipo crespa sob altas temperaturas em Cáceres - MT. Agrarian, 2:87-98.

Santos LL, Seabra Júnior S \& Nunes MCM (2010) Luminosidade, temperatura do ar e do solo em ambientes de cultivo protegido. Revista de Ciências Agro-Ambientais, 8:83- 93.

Schumacher PV, Mota JH, Yuri JE \& Resende GM (2012) Competição de cultivares de alface em Jataí-GO. Horticultura Brasileira, 30:S2727-S2731.

Seabra Junior S, Souza SBS de, Theodoro VC de A, Nunes MCM, Amorin R do C, Santos CL dos \& Neves LG (2009) Desempenho de cultivares de alface tipo crespa sob altas temperatura. In: $49^{\circ}$ Congresso de Olericultura, Maringá. Anais, ABH. CDROOM.

Seabra Junior S, Souza SBS, Neves LG, Theodoro VC de A, Nunes MCM, Nascimento AS, Rampazzo R, Luz AO \& Leão LL (2010) Desempenho de cultivares de alface tipo crespa sob diferentes telas de sombreamento no período de inverno. In: $50^{\circ}$ Congresso de Olericultura, Guarapari. Anais, ABH. CD-ROOM.

Silva EC, Leal NR \& Maluf WR (1999) Avaliação de cultivares de alface sob altas temperaturas em cultivo protegido em três épocas de plantio na região Norte-Fluminense. Ciência agrotecnologia, 23:491-499.

Silva S de AS \& Azevedo CAV (2002) Versão do programa computacional Assistat para o sistema operacional Windows. Revista Brasileira de Produtos Agroindustriais, 4:71-78.

Silva VF, Neto FB, Negreiros MZ de \& Pedrosa JF (2000) Comportamento de cultivares de alface em diferentes espaçamentos sob temperatura e luminosidade elevadas. Horticultura Brasileira, 18:183-187.

Rev. Ceres, Viçosa, v. 61, n.4, p. 558-566, jul/ago, 2014 
Souza JP, Freitas DB, Nogueira DH, Domingos FD, Vieira LA \& Batista MAV (2007) Comportamento de cultivares de alface no município de Iguatu-CE. In: $47^{\circ}$ Congresso de Olericultura, Porto Seguro. Anais, ABH. CD-ROM.

Tosta M da S, Borges F da SP, Reis LL dos, Tosta JS, Mendonça V \& Tosta P de AF (2009) Avaliação de quatro cultivares de alface para cultivo de outono em Cassilândia-MS. Agropecuária Científica no Semi-Árido, 5:30-35.
Trani PE \& Raij B van (1996) Hortaliças. In: Raij B van, Cantarella H, Quaggio JA \& Furlani AMC (Eds.) Recomendações de adubação e calagem para o estado de São Paulo. $2^{\text {a }}$ ed. Campinas, IAC. p.157-186. (Boletim técnico, 100). 